\title{
Enrichment of functional microbes and genes during pyrene degradation in two different soils
}

\author{
Songcan Chen ${ }^{1} \cdot$ Jingjing Peng ${ }^{2} \cdot$ Guilan Duan ${ }^{1}$
}

Received: 23 March 2015 / Accepted: 12 July 2015 / Published online: 12 August 2015

(C) Springer-Verlag Berlin Heidelberg 2015

\begin{abstract}
Purpose Stimulating microbial degradation is a promising strategy for the remediation of soils contaminated with polycyclic aromatic hydrocarbons (PAHs). To better understand the functional microbial populations and processes involved in pyrene biodegradation in situ, the dynamics of pyrene degradation and functional microbial abundance were monitored during pyrene incubation in soils. We hope our findings will provide new insights into in situ pyrene biodegradation in soils and help to identify functional microbes from soils. Materials and methods Pyrene $\left(60 \mathrm{mg} \mathrm{kg}^{-1}\right)$ was incubated with two different soils, one is lower PAH-containing agricultural soil (LS), and the other is higher PAH-containing industrial soil (HS). During incubation, triplicate samples were collected on days $0,3,7,14$, and 35 . Pyrene in soil samples was analyzed using an Agilent gas chromatograph (7890A) equipped with a mass-selective detector (model 5897). DNA in soils was extracted with a FastDNA Spin kit for soil (Bio101, USA). The abundance of functional microbes and genes was monitored by a Taqman or SYBR Green based realtime PCR quantification using an iCycler iQ5 themocycler (Bio-Rad, USA). The diversity of PAH-RHD $\alpha$ GP genes was evaluated by constructing clone libraries and sequencing.
\end{abstract}

Responsible editor: Chengrong Chen

Guilan Duan

duangl@rcees.ac.cn

1 State Key Lab of Urban and Regional Ecology, Research Center for Eco-Environmental Sciences, Chinese Academy of Sciences, Beijing 100085, China

2 Key Lab of Urban Environment and Health, Institute of Urban Environment, Chinese Academy of Sciences, Xiamen 361021, China
Results and discussion In both soils, more than $80 \%$ of the added pyrene was degraded within 35 days. After 35-day incubation, there was a significant enrichment of Gram-positive bacteria harboring PAH-ring hydroxylation dioxygenase (PAH-RHD $\alpha$ GP) genes, and the abundance of Mycobacterium increased significantly. In PAH-RHD $\alpha$ GP clone libraries from two soils, Mycobacterium was detected, while most sequences were closely related to uncultured Gram-positive bacteria. In addition, two pyrene catabolic pathways might be involved in pyrene degradation, as pyrene dioxygenase genes, nidA and nidA3, were dramatically enriched during incubation. Moreover, the abundance and diversity of potential degraders in two soils showed significantly difference in responding to pyrene stress. This result indicates that soil condition can significantly affect functional microbial populations and biological process for pyrene biodegradation. Conclusions These results revealed that Mycobacterium as well as uncultured Gram-positive $\mathrm{PAH}-\mathrm{RHD}_{\alpha}$ genotypes may be the important group of pyrene degraders in soils, and two pyrene catabolic pathways, targeted by nidA and nidA3, might potentially contribute to in situ biodegradation of pyrene. This study characterized the response pattern of potential pyrene degraders to pyrene stress in two different soils, which would increase our understanding of the indigenous processes of pyrene biodegradation in soil environment.

Keywords Abundance and diversity · Biodegradation . Pyrene $\cdot$ Soil

\section{Introduction}

High molecular weight polycyclic aromatic hydrocarbons (HMW-PAHs), comprised of at least three fused aromatic rings, are of special concern due to their toxicity, mutagenicity, 
carcinogenicity, and association with inflammatory vascular responses (Kim et al. 2005). Pyrene, arising from incomplete combustion of hydrocarbons, is a widespread HMW-PAH in the soil environment. Microbial degradation is the main process to remove PAHs from soil environment. Thus, a comprehensive understanding of the microbial degradation of pyrene will facilitate the development of new strategies to improve the remediation of PAH-polluted soils.

Many bacteria using pyrene as the sole carbon source have been isolated from various environments, most of them belong to genera Mycobacterium (Heitkamp et al. 1988) and Rhodococcus (Walter et al. 1991), which are Gram-positive. Recently, several Gram-negative strains have also been identified as pyrene degrader, such as Sphingomonas sp. (Zhong et al. 2011) and Pseudomonas aeruginosa RS1 (Ghosh et al. 2014). However, knowledge of pyrene-degrading bacterial populations is still limited and is mainly based on the studies of cultured bacteria. Therefore, the characterization of indigenous microbial populations would be necessary for a better understanding of in situ biodegradation processes of pyrene in complex environments, such as soil.

The initial step of PAH biodegradation commonly occurs via the incorporation of molecular oxygen into the aromatic nucleus by a multi-component terminal aromatic ring hydroxylating dioxygenase (RHD) enzyme system (Kauppi et al. 1998). RHD is composed of a large $\alpha$ subunit (PAH-RHD $\alpha$ ) and small $\beta$ subunits (Mason and Cammack 1992). Functional markers encoding PAH-RHD ${ }_{\alpha}$ can be used to specifically target functional microbial populations involved in PAH biodegradation (Dionisi et al. 2004). For example, PAH-RHD $\alpha$ from Gram-positive bacteria (PAH-RHD $\alpha$ GP) were shown to be involved and specialized in the degradation of HMW-PAHs (Baldwin et al. 2003; Zhou et al. 2006; Cebron et al. 2009). Two biochemical pathways of pyrene degradation have been established in pyrene-degrading mycobacterial strains (Kim et al. 2007). nidA, which was highly conserved in Mycobacterium (Heitkamp et al. 1988), encodes the $\alpha$-subunits of RHD that adds hydroxyl groups at C-4 and C-5 positions of pyrene in the degradation pathway (Kim et al. 2012). More recently, an alternative pyrene $\mathrm{RHD}_{\alpha}$ gene, nidA3, has been identified in Mycobacterium vanbaalenii PYR-1 (Kim et al. 2006), which was shown to be involved in the initial dihydroxylation step in an alternate detoxification pathway (Kim et al. 2007). Although the biochemical pathways of pyrene biodegradation have been identified in cultivated species, little is known about the in situ biodegradation pathways of pyrene in the soil environment. Moreover, how the abundance and diversity of potential pyrene degraders was influenced by soil environmental factors are not yet fully explored.

Therefore, the aim of the current study was to investigate the functional microbial populations and process involved in pyrene biodegradation in complex soil environment, including lower PAH-containing agricultural soil (LS) and higher PAH-containing industrial soil (HS). Total bacterial $16 \mathrm{~S}$ rDNA gene, PAH-RHD $\alpha$ GP gene, and Mycobacteria $16 \mathrm{~S}$ rDNA gene copies were regularly measured by realtime PCR to identify the potential pyrene degraders in soils. The abundance of functional genes, nidA and nidA3, was also monitored to characterize the likely mechanisms of pyrene biodegradation pathways in two soils.

\section{Materials and methods}

\subsection{Soil property and preparing}

Surface soils $(0-20 \mathrm{~cm})$ were collected from the suburb of Beijing, China. One was from an agricultural field with less PAH contamination $\left(40^{\circ} 17.54 \mathrm{~N} ; 116^{\circ} 06.81 \mathrm{E}\right)(\mathrm{LS})$. This field is perennially planted with vegetables and corn. When we sampled soil, corn was grown at the field. The other soil was from an industrial green land. This land was long-term contaminated with PAHs, which is near a steel-manufacturing factory $\left(39^{\circ} 54.57 \mathrm{~N} ; 116^{\circ} 08.54 \mathrm{E}\right)(\mathrm{HS})$. When we sampled soil, the land was covered with grass. Both soils are traditional cinnamon soil, which are classified as alfsol according to the US Department of Agriculture soil classification system. After being transported to laboratory, soil samples were air-dried, sieved $(2 \mathrm{~mm})$, and stored in the dark at $4{ }^{\circ} \mathrm{C}$. The soil properties were determined following standard procedures and are shown in Table 1. The LS is silty clay loam, and the HS is clay loam. The $\mathrm{pH}$ and content of silt, clay, and organic matter of two soils were comparable, while the content of sand of agricultural soil was lower than that of industrial soil. Significantly, the concentration of total PAHs of industrial soil (HS) was 6.3-fold higher than that of agricultural soil (LS), and the pyrene concentration was almost 10 -fold higher than that of agricultural soil.

Table 1 Properties of soils from lower PAH-containing soil (LS) and higher PAH-containingsoil (HS)

\begin{tabular}{|c|c|c|}
\hline Properties & $\begin{array}{l}\text { Lower PAH-containing } \\
\text { soil (LS) }\end{array}$ & $\begin{array}{l}\text { Higher PAH-containing } \\
\text { soil (HS) }\end{array}$ \\
\hline Soil texture & Silty clay loam & Clay loam \\
\hline Sand $(\%)$ & 13.32 & 22.38 \\
\hline Silt (\%) & 50.23 & 39.47 \\
\hline Clay (\%) & 36.46 & 38.15 \\
\hline $\mathrm{pH}$ & 8.10 & 8.03 \\
\hline $\begin{array}{l}\text { Organic matter } \\
\qquad\left(\mathrm{g} \mathrm{kg}^{-1}\right)\end{array}$ & 20.81 & 24.27 \\
\hline $\begin{array}{l}\text { Total PAHs } \\
\qquad\left(\mathrm{mg} \mathrm{kg}^{-1}\right)\end{array}$ & 1.097 & 6.933 \\
\hline Pyrene (mg kg ${ }^{-1}$ ) & 0.042 & 0.409 \\
\hline
\end{tabular}




\subsection{Pyrene incubation experiment}

In order to re-activate the soil microorganisms, dry soil samples $(800 \mathrm{~g})$ in duplicates were placed in separate glass beakers, moistened with sterile distilled water to the level at $50 \%$ of water holding capacity, and incubated at room temperature $\left(25^{\circ} \mathrm{C}\right)$ for 2 weeks. The soils were then spiked with $1000 \mathrm{mg} \mathrm{l}^{-1}$ solution of pyrene in acetone to a final concentration at $60 \mathrm{mg} \mathrm{kg}^{-1}$, following the methods recommended by Brinch et al. (2002) with some adaptations. Briefly, a subsample of $10 \%$ soil was spiked with the pyrene solution and mixed throughout. After evaporation of the acetone (overnight at $\left.25^{\circ} \mathrm{C}\right)$, the spiked subsample $(10 \%)$ was mixed with the rest $(90 \%)$ of the soil and shaken thoroughly. The moisture content of the samples was adjusted again to $50 \%$ of water holding capacity. For unspiked control, soils were amended with the same amount of acetone as the pyrene-spiked soils. For the abiotic controls, the soils were autoclaved before spiking with pyrene solution (Park and Crowley 2006).

After the treated soils were homogenized, 10-g aliquots were placed into serum bottle and incubated in the dark at $25^{\circ} \mathrm{C}$. During incubation, triplicate samples were collected on days $0,3,7,14$, and 35 , frozen immediately, and stored at $-80{ }^{\circ} \mathrm{C}$ until analyses.

\subsection{Pyrene quantification}

Pyrene was extracted from $2 \mathrm{~g}$ soils which were dried by lyophilization and measured by accelerated solvent extractor (Dionex ASE-300). Analysis of pyrene followed the procedure described earlier (Zhang et al. 2011). Briefly, $100 \mathrm{mg} \mathrm{kg}^{-1}$ of fluoranthene-d10 and phenantherene-d10 were used as substitute and internal standards, respectively. Concentrated $(1 \mathrm{ml})$ soil extracts were analyzed using an Agilent gas chromatograph (7890A) equipped with a massselective detector (model 5897): Helium was used as a carrier gas (constant velocity of $30 \mathrm{~cm} \mathrm{~s}^{-1}$ ) at $250{ }^{\circ} \mathrm{C}$. The $\mathrm{GC}$ oven conditions are as follows: $50^{\circ} \mathrm{C}$ for $1 \mathrm{~min}, \mathrm{a} 10^{\circ} \mathrm{C} \mathrm{min}^{-1} \mathrm{ramp}$ to $250^{\circ} \mathrm{C}$, and then a ramp of $5{ }^{\circ} \mathrm{C} \mathrm{min}{ }^{-1}$ to final temperature of $280^{\circ} \mathrm{C}$ (hold for $10 \mathrm{~min}$ ). Mass spectrometer detection was used with the selected ion monitoring system. Each treatment was carried out in triplicate. Analytical procedural blanks and fluorene-d10 (surrogate for pyrene) were used for quality control. Pyrene concentrations of analytical procedural blanks were very low $\left(<0.01 \mathrm{mg} \mathrm{kg}^{-1}\right)$, which were about 4 orders of magnitude lower than that of the soil samples. The average recovery efficiency of fluorene-d 10 (surrogate for pyrene) was $89.1 \pm 7.2 \%$. The final sample concentrations were blank corrected, but not surrogate recovery corrected. In addition, the recovery of the pyrene from the freshly spiked soils (on day 0 ) was $104.6 \pm 4.4 \%$, indicating that the spiking procedures were validated.

\subsection{Primer development}

To design nidA3 targeted primer, the DNA sequences of nidA3 gene from several PAH-degrading Mycobacterium strainsPYR-1 (AF249301), 6PYR (AJ494745), JLS (AY330098), KMS (AY330100), and MCS (AY33010)-were obtained from NCBI GenBank (http://www.ncbi.nlm.nih.gov/) and aligned by MEGA5 software (Tamura et al. 2011). Conserved regions of nidA3 were selected from the aligned data, and three sets of real-time PCR primers targeting different regions of the nidA3 gene were designed by Primer Premier 5.0 software (Premier Biosoft International, USA). Among these, one primer set was chosen for real-time PCR analysis. To ensure specificity of the designed primer, ten cloned products from one of our DNA samples were sequenced, all showing more than $98 \%$ amino acid similarity with PAH-degrading Mycobacterium sp. NidA3 (data not shown).

\subsection{DNA extraction and real-time PCR analysis}

DNA was extracted from $0.5 \mathrm{~g}$ of soil (dry weight) with a FastDNA Spin kit for soil (Bio101, USA) according to the manufacturer's instructions. The concentration and quality of the extracted DNA were determined by spectrophotometer analysis (NanoDrop ND-1000, NanoDrop Technologies, Willmington, DE) and agarose gel electrophoresis.

Total bacterial (16S rDNA), Gram-positive PAH-RHD ${ }_{\alpha}$ gene (PAH-RHD $\alpha$ GP), Gram-negative PAH-RHD $\alpha$ gene (PAH-RHD $\alpha$ GN), Mycobacteria 16S rDNA, and nidA and nidA3 gene copies were evaluated by a Taqman or SYBR Green based real-time PCR quantification using an iCycler iQ5 themocycler (Bio-Rad, USA), and their primes and amplification protocols were summarized in Table 2. Tenfold serial dilutions of a known copy number of the plasmid DNA were generated to produce the standard curve. Each sample DNA was diluted for minimizing threshold cycle suppression by inhibitors for that sample type (typically $1: 10$ ). The real-time PCR efficiencies (87.9 112.5 \%) were examined to test for inhibition. $R^{2}$ values were more than 0.99 for all calibration curves. All real-time PCR analyses were performed using iCycler software.

\subsection{PAH-RHD $\alpha$ GP gene clone library construction and sequencing}

Two clone libraries were constructed from LS and HS at day 35. The PCR amplification using the primers GP-F/GP-R is described in Table 2. PCR products were purified and ligated into the pMD19-T easy vector (Promega, USA) according to the manufacturer's instructions. Plasmids were transformed into Escherichia coli JM109 cells (Takara), and more than 50 clones were randomly selected and sequenced for each 
Table 2 Quantitative real-time PCR primers in this study

\begin{tabular}{|c|c|c|c|c|c|}
\hline Target group & Primers & Squences $\left(5^{\prime}->3^{\prime}\right)$ & Length & $\begin{array}{l}\text { Annealing } \\
\text { temperature }\end{array}$ & Reference \\
\hline \multirow[t]{3}{*}{ Bacateria (16S rDNA) } & BACT1369F & CGGTGAATACGTTCYCGG & \multirow[t]{3}{*}{$103 \mathrm{bp}$} & \multirow[t]{3}{*}{$56{ }^{\circ} \mathrm{C}$} & \multirow[t]{3}{*}{ Suzuki et al. 2000} \\
\hline & BACT1492R & GGWTACCTTGTTACGACTT & & & \\
\hline & Probe (TM1389F) & FAM-CTTGTACACACCGCCCGTC-TAMRA & & & \\
\hline \multirow[t]{2}{*}{ Gram positive PAH-RHD $\alpha$} & PAH-RHD $\alpha$ GP-F & CGGCGCCGACAAYTTYGTNGG & \multirow[t]{2}{*}{$292 \mathrm{bp}$} & \multirow[t]{2}{*}{$54{ }^{\circ} \mathrm{C}$} & \multirow[t]{2}{*}{ Cebron et al. 2008} \\
\hline & GP-R & GGGGAACACGGTGCCRTGDATRAA & & & \\
\hline \multirow[t]{2}{*}{ Gram negative PAH-RHD $\alpha$} & GN-F & GAGATGCATACCACGTKGGTTGGA & \multirow[t]{2}{*}{$306 \mathrm{bp}$} & \multirow[t]{2}{*}{$56^{\circ} \mathrm{C}$} & \multirow[t]{2}{*}{ Cebron et al. 2008} \\
\hline & GN-R & AGCTGTTGTTCGGGAAGAYWGTGCMGTT & & & \\
\hline \multirow[t]{2}{*}{ Mycobacteria (16S rDNA) } & Myco-F & CATGCAAGTCGAACGGAAA & \multirow[t]{2}{*}{$534 \mathrm{bp}$} & \multirow[t]{2}{*}{$59{ }^{\circ} \mathrm{C}$} & \multirow[t]{2}{*}{ Leys et al. 2005} \\
\hline & Myco-R & TGTGAGTTTTCACGAACA & & & \\
\hline \multirow[t]{2}{*}{ nidA } & NidA-F & TTCCCGAGTACGAGGGATAC & \multirow[t]{2}{*}{$121 \mathrm{bp}$} & \multirow[t]{2}{*}{$56{ }^{\circ} \mathrm{C}$} & \multirow[t]{2}{*}{ DeBruyn et al. 2007} \\
\hline & NidA-R & TCACGTTGATGAACGACAAA & & & \\
\hline \multirow[t]{2}{*}{ nidA3 } & NidA3-F & CCTGATGCGACGACAATG & \multirow[t]{2}{*}{$421 \mathrm{bp}$} & \multirow[t]{2}{*}{$55^{\circ} \mathrm{C}$} & \multirow[t]{2}{*}{ This study } \\
\hline & NidA3-R & GCAACCCTAGCCGACTCTT & & & \\
\hline
\end{tabular}

clone library. All the sequences and their relatives obtained from the NCBI were aligned by using the MEGA5 software. The sequences with more than $97 \%$ identity were grouped into one operational taxonomic unit (OTU) using the Mothur program (version 1.31.2, USA) by the furthest neighbor approach. Phylogenetic tree was created using the MEGA5 software by neighbor joining (NJ) method. The relative confidence of the tree topologies was evaluated by performing 1000 bootstrap replicates.

\section{Results}

\subsection{Pyrene dissipation}

The kinetics of pyrene dissipation in the two soils was monitored during incubation on days $0,3,7,14$, and 35 . In the unautoclaved soils, pyrene dissipation exhibited similar trends over time in both soils, with an initial lag phase followed by a rapid disappearance (Fig. 1). From day 7, the dissipation of pyrene was noticeable, while no significant difference was observed between two soils. At day 35, more than $80 \%$ of the spiked pyrene was dissipated in both soils. The pyrene dissipation rate was $1.30 \mu \mathrm{g}_{\text {day }}{ }^{-1} \mathrm{~g}^{-1}$ dry soil in LS; however, the pyrene dissipation rate was significantly higher in $\mathrm{HS}$, about $1.60 \mu \mathrm{g}$ day $^{-1} \mathrm{~g}^{-1}$ dry soil. In contrast, for the sterilized soils, there was little pyrene disappearance observed during the whole incubation. Moreover, a slight increase of pyrene levels was observed at the initial incubation phase (at day 3 and day 7), although the increase was not significant (ANOVA, $P>0.05$ ). This result suggests that abiotic dissipation of pyrene is not a main route for pyrene removal in soils.

\subsection{Quantification of the potential pyrene degraders and functional genes}

Total bacterial 16S rDNA gene copies were determined by real-time PCR. For two soils, the amount of bacterial $16 \mathrm{~S}$ rDNA was relatively constant over time, either spiked with or without pyrene, with the gene copies ranging from $8.9 \times$ $10^{9}$ to $1.9 \times 10^{10}$ copies $^{-1}$ dry weight soil (Fig. 2).

Across the entire incubation times, the quantities of PAH$\mathrm{RHD}_{\alpha}$ GP gene, Mycobacteria 16S rDNA gene, nidA (from Mycobacteria), and nidA3 (from Mycobacteria) increased significantly in both soils spiked with pyrene. For both soils, PAH-RHD ${ }_{\alpha}$ GP gene copies significantly $(P<0.01)$ increased with incubation time (Fig. 2). The copies of Mycobacteria $16 \mathrm{~S}$ rDNA, measured by an assay specific to fast-growing Mycobacteria, increased by 5 and 20 times in LS and HS,

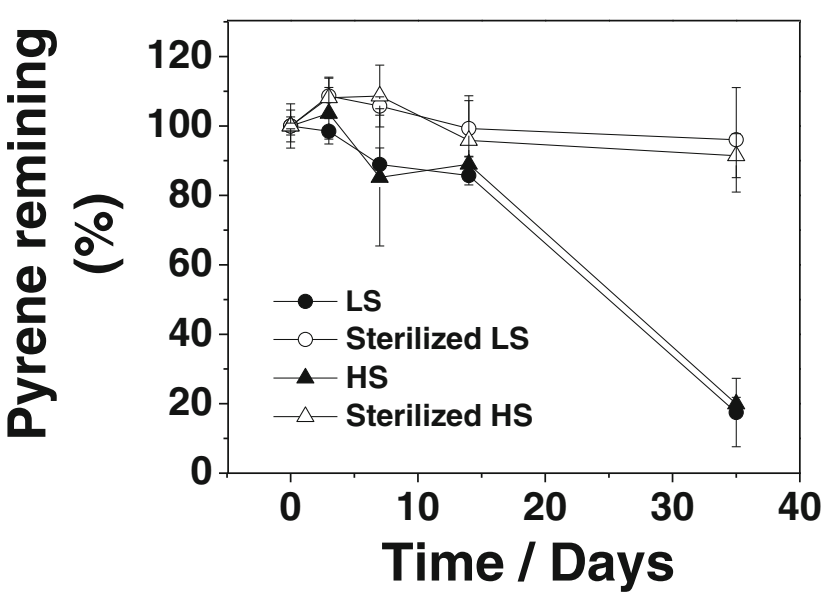

Fig. 1 Pyrene dissipation in the soils during incubation with pyrene. Soils were spiked with $60 \mathrm{mg} \mathrm{kg}^{-1}$ pyrene; $L S$ less PAH-contaminated soil, $H S$ higher PAH-containing soil; data are means \pm SE; $n=3$ 
Fig. 2 Quantification of bacterial 16S rDNA, PAH-RHD $\alpha$ GP, Mycobacterium 16S rDNA, nidA, and nidA3 gene copies during incubation; + pyrene, spiked with $60 \mathrm{mg} \mathrm{kg}^{-1}$ pyrene; - pyrene, unspiked with pyrene; data are means \pm SE; $n=3$

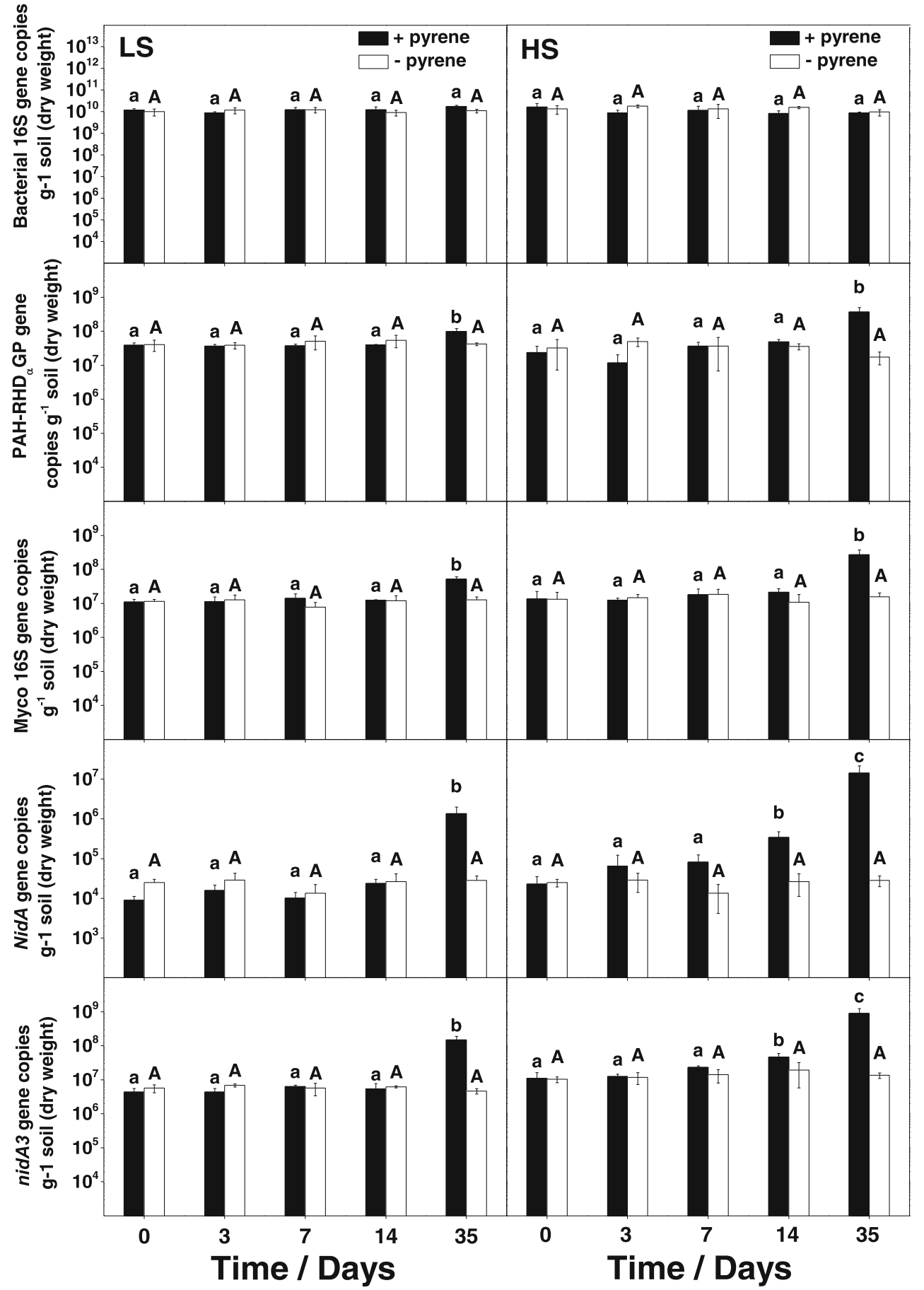

respectively, after 35 days of pyrene incubation (Fig. 2). Copy numbers of genes, nidA and nidA3, encoding alpha subunits of two different ring hydroxylating dioxygenases, showed approximately 2 orders of magnitude higher at the end of experiment ( 35 days) in both soils compared with those at the beginning (Fig. 2). In contrast to pyrene-spiked soils, none of these detected genes showed significant changes in both soils without pyrene (Fig. 2). These results suggested that pyrene incubation increased the abundance of Mycobacteria and the expression of nidA and nidA3.

Between two pyrene-spiked soils sampled at day 35 , there was a significant difference in abundances of PAH-RHD ${ }_{\alpha}$ GP gene, Mycobacteria 16S rDNA, nidA, and nidA3: all exhibited significantly higher copies at HS than at LS (Fig. 2). In addition, at the initial time of pyrene incubation (day 0 ), there was no significant difference in quantities of Mycobacteria 
$16 \mathrm{~S}$ rDNA or PAH-RHD $\alpha$ GP genes between two soils, while HS had significantly higher nidA and nidA3 copy numbers than LS (Fig. 2). These observations were consistent with the fact that soil HS had experienced the historical contamination and typically exhibited higher concentration of PAHs than LS (Table 1).

\subsection{Correlations among catabolic genotypes and pyrene degradation}

To determine the relationship between catabolic gene copies which may be related to the degradation potential of the microbial communities, a correlation matrix of Spearman rank correlation coefficients was developed (Table 3). As shown in Table 3, the extent of pyrene degradation was positively correlated to all the target gene copies except bacterial $16 \mathrm{~S}$ rDNA. In addition, Mycobacteria $16 \mathrm{~S}$ rDNA, nidA, and nidA3 gene copies had significant positive correlations with each other. This is expected as Mycobacterium spp. are the primary carriers of nidA or nidA3 genotypes in the contaminated environment (DeBruyn et al. 2012).

\subsection{Diversity of PAH-RHD $\alpha$ GP genes}

To investigate the diversity of PAH-RHD $\alpha$ GP genes, two clone libraries were constructed from pyrene-spiked LS and HS at day 35, respectively. A total of 10 OTUs were identified in the clone library of the LS (46 sequences analyzed), and 4 OTUs were identified in the clone library of the HS (43 sequences analyzed). The richness indices (Table 4), including Chao 1 estimator, Shannon index, and reciprocal of Simpson index, revealed that a higher diversity of PAH-RHD ${ }_{\alpha}$ GP gene was found in the pyrene-spiked LS than in the HS, and this was consistent with the result of the OTU richness curves

Table 3 Spearman rank correlation coefficient $\left(r_{\mathrm{s}}\right)$ matrix $(n=10)$

\begin{tabular}{lllllll}
\hline Parameter $^{\mathrm{a}}$ & PyrDeg & $16 S$ & Myco & nidA & nidA3 & GP \\
\hline PyrDeg & 1.00 & & & & & \\
l6S & 0.28 & 1.00 & & & & \\
Myco & $0.72^{*}$ & 0.20 & 1.00 & & & \\
nidA & $0.67^{*}$ & 0.04 & $0.84^{* *}$ & 1.00 & & \\
nidA3 & $0.63^{*}$ & 0.14 & $0.92^{* *}$ & $0.98^{* *}$ & 1.00 & \\
GP & $0.72^{*}$ & 0.02 & 0.58 & 0.54 & 0.50 & 1.00
\end{tabular}

Significant correlation is marked with asterisks $(*$ at $<0.05$ level, $* *$ at $<0.01$ level)

${ }^{a}$ PyrDeg is the percentage of spiked pyrene degradation during incubation; 16S, Myco, nidA, nidA3, and GP are abundance of bacterial 16S rDNA, Mycobacteria 16S rDNA nidA, nidA3, and PAH-RHD $\alpha$ GP genes, respectively
(Fig. 3), which showed representative sampling of each clone library.

The phylogenetic analysis indicated that all of the obtained sequences of PAH-RHD ${ }_{\alpha}$ GP gene from LS and HS could be grouped into three distinct gene clusters (Fig. 4). Cluster I was the largest group and included a total of $80 \mathrm{PAH}^{-\mathrm{RHD}_{\alpha} \mathrm{GP}}$ gene sequences. Among cluster I, five and four sequences from soil LS and HS, respectively, were closely related to nidA3 of Mycobacterium. However, most sequence from cluster I could not be closely clustered with any functional gene characterized in cultivated microorganisms. They were affiliated with uncultured PAH-RHD $\alpha$ genes recovered from HMW-PAH-contaminated environment and were related to nidA3 from Mycobacterium with approximately $90 \%$ similarity. Cluster II included three sequences from LS and five sequences from HS. These sequences were closely related to an uncultured Actinobacteria $\mathrm{PAH}-\mathrm{RHD}_{\alpha}$ gene and could be clustered with $p d o A 2$ derived from two cultivated Mycobacterium species. Cluster III contained only 1 sequence from LS, which was not closely related (with less than $87 \%$ similarity) to any reported sequences available in public database. This suggested the existence of novel PAH-RHD $\alpha$ GP gene or microorganism in LS.

\section{Discussion}

\subsection{Dissipation of pyrene}

Results from this study showed that the majority of added pyrene was dissipated in two soils after 35 days of incubation (Fig. 1). Compared with previous findings (Chen and Ding 2012; Peng et al. 2010; Xu et al. 2006), pyrene dissipation in both soils was relatively more rapid in this study. It was likely due to the rapid enrichment of activated indigenous degraders in response to the presence of pyrene, which would result in higher pyrene degradation (>96\%) in 1-month incubation (Hamdi et al. 2007). However, the rapid pyrene dissipation was not observed in the sterilized soils; this result suggests that pyrene dissipation in soil environment mainly relies on microbial degradation biotic process, rather than abiotic process. It was concerned that, under high content of organic matter and clay condition, abiotic PAH loss might also contribute to pyrene dissipation (e.g., sequestrated by soil matrix). However, in our study, no significant (ANOVA, $p>0.05$ ) pyrene disappearance was observed in both sterilized soils over the incubation time (Fig. 1). We assumed that it was possible due to the time of aging being relatively short. This observation was consistent with the previously published data obtained from other PAH aging studies using sterilized soils (Luo et al. 2012; Macleod and Semple 2000; Cheung and Kinkle 2001; Mueller 2006). 
Table 4 Diversity and richness indices of PAH-RHD $\alpha$ GP gene sequences from two pyrene spiked soils

\begin{tabular}{lllllll}
\hline Soil & Clone number & OTUs $^{\mathrm{a}}$ & Chao1 $^{\mathrm{b}}$ & Shannon $^{\mathrm{c}}$ & 1/Simpson $^{\mathrm{d}}$ & Coverage (\%) $^{\mathrm{e}}$ \\
\hline HS & 46 & 10 & 17.5 & 1.53 & 3.39 & 84.80 \\
LS & 43 & 4 & 4.0 & 0.72 & 1.58 & 100 \\
\hline
\end{tabular}

OTU operational taxonomic unit, $H S$ higher PAH-containing industrial soil, $L S$ lower PAH-containing agricultural soil

${ }^{\text {a }}$ OTUs are defined at $3 \%$ nucleotide acid divergence

${ }^{\mathrm{b}}$ Nonparametric statistical predictions of total richness of OTUs based on the distribution of singletons and doubletons

${ }^{\mathrm{c}}$ Shannon diversity index. A higher number represents more diversity

${ }^{\mathrm{d}}$ Reciprocal of Simpson's diversity index. A higher number represents more diversity

\subsection{Enrichment of functional microbes during pyrene degradation}

To unravel the response of microbial populations in soils to pyrene pollution, real-time PCR based assay for potential functional microbes and genes was conducted under different soil environments. Specially, we quantified the bacterial $16 \mathrm{~S}$ rDNA, PAH-RHD ${ }_{\alpha}$ GP, Mycobacteria $16 \mathrm{~S}$ rDNA, nidA, and nidA3 gene abundances in two pyrene-spiked soils. The amount of bacterial 16S rDNA genes, a proxy for bacterial biomass (Suzuki et al. 2000), was relatively stable over time in both soils regardless of the addition of pyrene or not (Fig. 2). This result indicates that there was no significant change in the overall population density of the total bacteria in soils exposed to pyrene. This observation is similar to previous studies showing that $16 \mathrm{~S}$ rDNA gene copy numbers were not affected by the addition of PAHs including pyrene, phenanthrene, and naphthalene (Park and Crowley 2006; Peng et al. 2010; Niepceron et al. 2014). However, the relatively constant density for the bacterial biomass did not rule out variations in the species composition of the bacterial community.

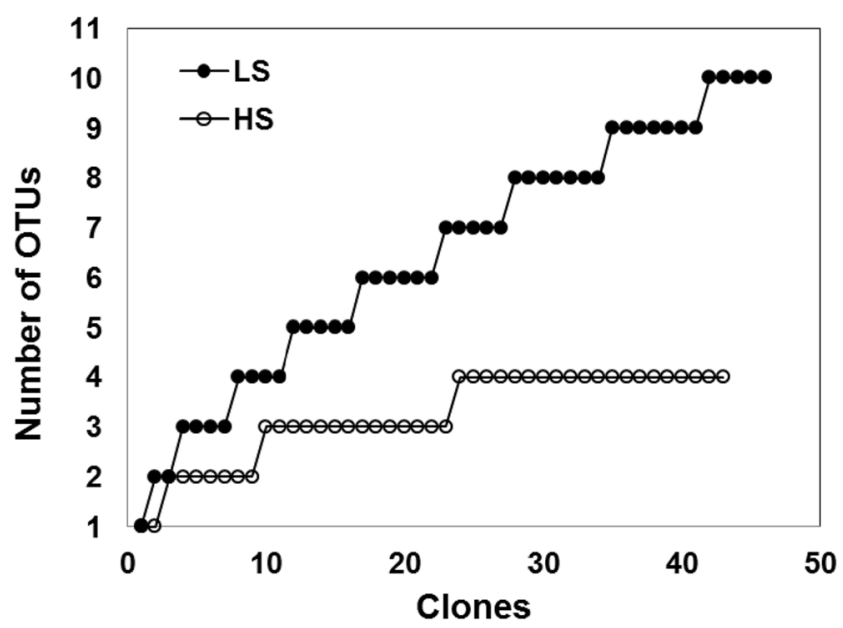

Fig. 3 OTU richness curves of PAH-RHD $\alpha$ GP gene libraries. The curves were obtained by rarefaction calculations of OTU abundance data and they represent libraries from two pyrene-spiked soils. Curves were calculated for $97 \%$ sequence identity
In order to further study the functional microbial population that might be involved in pyrene biodegradation in two soils, we monitored the bacterial PAH degradation community using primers targeting PAH-RHD $\alpha$ GP genes from a wide range of bacteria taxa (Gram-positive) (Fig. 2). The increasing abundance of PAH-RHD ${ }_{\alpha}$ GP gene over the incubation times with pyrene indicated that the Gram-positive bacteria harboring PAH-RHD ${ }_{\alpha}$ genes might be an important group of pyrene degraders in the test soils. Previous studies have implied that Gram-positive PAH degrader was the predominant PAH degrading microbial group in an industrial soil, where high concentrations of pyrene were detected (Meng and Zhu 2011). Gram-positive degraders might experience advantages in pyrene biodegradation by increasing pyrene bioavailability through forming biofilm directly on hydrophobic pollutants (Johnsen and Karlson 2004).

Sequencing of PAH-RHD $\alpha$ GP clone library was done to examine the phylogenetic distribution of the potential pyrene degraders in two tested soils (Fig. 4). Several sequences detected in LS and HS were closely related to nidA3 of Mycobacterium with more than $98 \%$ nucleotide sequence identity, indicating the involvement of fast-growing Mycobacterium in pyrene biodegradation. However, the majority of retrieved sequences ( 40 of 46 clones in LS, 39 of 43 clones in HS) were closely related to PAH-RHD $\alpha$ genes derived from uncultured bacteria (Fig. 4). These genes might be a potential pyrene dioxygenase, as they showed more than $90 \%$ nucleotide acid similarity with either nidA3 or pdoA2 from Mycobacterium (Fig. 4), which were considered as the key catabolic genes to degrade pyrene (Krivobok et al. 2003; Kim et al. 2006). These results suggested that Mycobacterium as well as those uncultured bacteria might play an important role in pyrene degradation. The identity of these uncultured bacteria should be further investigated by cultivationindependent approaches such as stable-isotope probing (SIP) (Peng et al. 2013).

To investigate the response of Mycobacteria, detected in PAH-RHD $\alpha$ GP clone library, to the addition of pyrene, Mycobacteria 16S rDNA gene was quantified in two pyrene-spiked soils during incubation times (Fig. 2). Results 
Fig. 4 Neighbor-joining tree based on the multiple alignments of PAH-RHD $\alpha$ GP gene sequences. Bootstrap values represent 1000 replicates and only values above $50 \%$ are shown. The scale bar represents the expected number of changes per nucleotide position (5\% nucleotide substitution). Numbers in parentheses (in bold) after the clone names correspond to the analyzed clone numbers

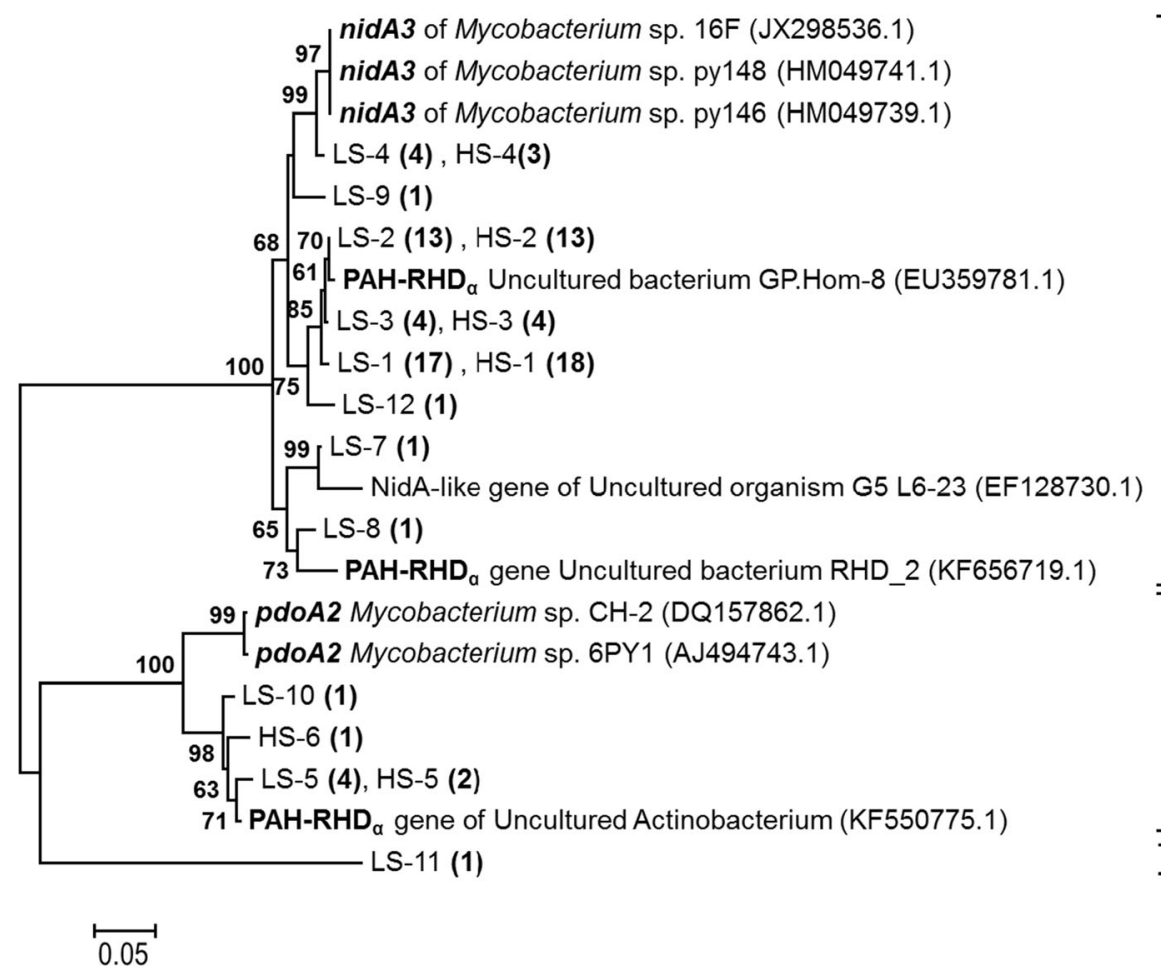

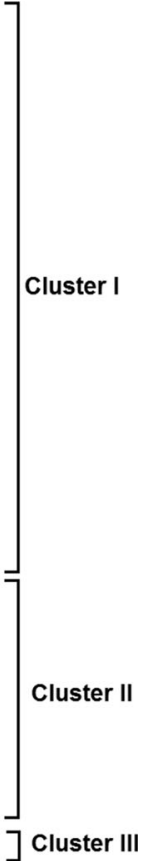

Cluster III showed that the fast-growing Mycobacteria was presented and enriched during the pyrene biodegradation in both soils. This result indicates that Mycobacteria were induced to grow and were likely playing an important role in pyrene degradation. Previous studies also showed that fast-growing Mycobacteria populations were an important group of HMW-PAH (e.g., pyrene) degrader in PAH-contaminated soils (DeBruyn et al. 2007; Debruyn et al. 2009). Coincident with the detection of fast-growing Mycobacteria, the copy numbers of pyrene dioxygenase genes including Mycobacteria nidA and nidA3 increased significantly during incubation time (Fig. 2), which further suggested that fastgrowing Mycobacteria were enriched in the test soils and had function genotypes for pyrene conversion. However, we could not exclude the possibility of other nidA or nidA3 carriers, such as Terrabacter spp., Phycicoccus spp., and Leifsonia spp. (DeBruyn et al. 2012), which might also be involved in pyrene biodegradation.

\subsection{Enrichment of functional gene during pyrene degradation}

The positive correlation between pyrene catabolic gene copies (nidA and nidA3) and pyrene degradation extent indicated that two pyrene catabolic pathways, targeted by nidA (degradation pathway) and nidA3 (detoxification pathway), respectively, might both potentially contribute to the pyrene biodegradation in the tested soils (Table 3). Although the in situ metabolic activity of nidA and nidA3 genes (detected as mRNA transcripts) remains to be established, it is likely that presence of catabolic genes could serve as markers of their actual function. For example, in the case of PAH-degrading communities, strong positive correlations have previously been found between nahAc ( $\alpha$ subunit of naphthalene dioxygenase) gene copies and transcripts, indicating that the presence of catabolic genes in a community is related to their activity (Fleming et al. 1993; Yagi and Madsen 2009). Thus, our observations implied that both nidA and nidA3 genes might play metabolic roles in pyrene biodegradation in contaminated soils, and they might provide useful targets for monitoring HMW-PAH degradation. As this is, to our knowledge, the first quantitative detection of nidA3 in PAH-degrading communities, this also presents the first demonstration of a link between nidA3 abundance to function (pyrene biodegradation) in indigenous microbial communities.

\subsection{Different response patterns of functional microbial community between two soils}

Notably, functional microbial community potentially involved in pyrene biodegradation in two soils showed different abundance and diversity after exposure to pyrene, indicating a soil condition dependent response of the functional soil bacteria to pyrene contamination. The abundances of $\mathrm{PAH}_{-\mathrm{RHD}_{\alpha} \mathrm{GP}}$ gene, Mycobacterium 16S rDNA, nidA, and nidA3 were approximately 1 order of magnitude higher in HS after spiking with pyrene than in the LS detected at day 35 (Fig. 2). These results might be due to (1) the initial abundance of these 
functional genes in HS being already higher than in LS before artificial pyrene spiking, and (2) the more rapidly growing of microbial populations carrying functional genes in HS (Ding et al. 2010). The diversity of the PAH-RHD $\alpha$ GP genes was lower in HS than in LS after 35 days of pyrene incubation based on the value of the Shannon index and reciprocal of Simpson (Table 4). These differences in functional microbial community structure between two soils might attribute to lower initial microbial diversity in HS, which was heavily contaminated by PAHs. Previous studies showed that indigenous microbial communities in heavily PAH-contaminated soils were less diverse than those in less contaminated areas due to the toxicity of PAHs (Smalla et al. 2007).

\section{Conclusions}

In conclusion, this study revealed that Mycobacterium as well as uncultured Gram-positive PAH-RHD ${ }_{\alpha}$ genotypes may be the important group of pyrene degraders in soils, and two pyrene catabolic pathways, targeted by nidA and nidA3, might potentially contribute to in situ biodegradation of pyrene. Moreover, the soil environment was indicated to significantly affect the response of functional microbial populations and biological process to pyrene spiking. These findings provide new insights into in situ pyrene biodegradation in soils and help to identify functional microbes from different soils.

Acknowledgments This research was supported by the National Basic Research (973) Program of China (No. 2014CB441102).

\section{References}

Baldwin BR, Nakatsu CH, Nies L (2003) Detection and enumeration of aromatic oxygenase genes by multiplex and real-time PCR. Appl Environ Microbiol 69:3350-3358

Brinch UC, Ekelund F, Jacobsen CS (2002) Method for spiking soil samples with organic compounds. Appl Environ Microbiol 68: 1808-1816

Cebron A, Norini MP, Beguiristain T, Leyval C (2008) Real-Time PCR quantification of PAH-ring hydroxylating dioxygenase (PAH-RHD alpha) genes from gram positive and gram negative bacteria in soil and sediment samples. J Microbiol Meth 73:148-159

Cebron A, Beguiristain T, Faure P, Norini MP, Masfaraud JF, Leyval C (2009) Influence of vegetation on the in situ bacterial community and polycyclic aromatic hydrocarbon $(\mathrm{PAH})$ degraders in aged PAH-contaminated or thermal-desorption-treated soil. Appl Environ Microbiol 75:6322-6330

Chen BL, Ding J (2012) Biosorption and biodegradation of phenanthrene and pyrene in sterilized and unsterilized soil slurry systems stimulated by Phanerochaete chrysosporium. J Hazard Mater 229:159169

Cheung PY, Kinkle BK (2001) Mycobacterium diversity and pyrene mineralization in petroleum-contaminated soils. Appl Environ Microb 67:2222-2229
DeBruyn JM, Chewning CS, Sayler GS (2007) Comparative quantitative prevalence of Mycobacteria and functionally abundant nidA, nahAc, and nagAc dioxygenase genes in coal tar contaminated sediments. Environ Sci Technol 41:5426-5432

Debruyn JM, Mead TJ, Wilhelm SW, Sayler GS (2009) PAH biodegradative genotypes in Lake Erie sediments: evidence for broad geographical distribution of pyrene-degrading mycobacteria. Environ Sci Technol 43:3467-3473

DeBruyn JM, Mead TJ, Sayler GS (2012) Horizontal transfer of PAH catabolism genes in Mycobacterium: evidence from comparative genomics and isolated pyrene-degrading bacteria. Environ Sci Technol 46:99-106

Ding GC, Heuer H, Zuhlke S, Spiteller M, Pronk GJ, Heister K, KogelKnabner I, Smalla K (2010) Soil type-dependent responses to phenanthrene as revealed by determining the diversity and abundance of polycyclic aromatic hydrocarbon ring-hydroxylating dioxygenase genes by using a novel PCR detection system. Appl Environ Microbiol 76:4765-4771

Dionisi HM, Chewning CS, Morgan KH, Menn FM, Easter JP, Sayler GS (2004) Abundance of dioxygenase genes similar to Ralstonia sp. strain U2 nagAc is correlated with naphthalene concentrations in coal tar-contaminated freshwater sediments. Appl Environ Microbiol 70:3988-3995

Ghosh I, Jasmine J, Mukherji S (2014) Biodegradation of pyrene by a Pseudomonas aeruginosa strain RS1 isolated from refinery sludge. Bioresource Technol 166:548-558

Hamdi H, Benzarti S, Manusadzianas L, Aoyama I, Jedidi N (2007) Bioaugmentation and blostimulation effects on PAH dissipation and soil ecotoxicity under controlled conditions. Soil Biol Biochem 39:1926-1935

Heitkamp MA, Freeman JP, Miller DW, Cerniglia CE (1988) Pyrene degradation by a Mycobacterium sp - identification of ring oxidation and ring fission-products. Appl Environ Microbiol 54:2556-2565

Johnsen AR, Karlson U (2004) Evaluation of bacterial strategies to promote the bioavailability of polycyclic aromatic hydrocarbons. Appl Microbiol Biot 63:452-459

Kauppi B, Lee K, Carredano E, Parales R, Gibson D, Eklund H, Ramaswamy S (1998) Structure of an aromatic-ring-hydroxylating dioxygenase naphthalene 1, 2-dioxygenase. Structure 6:571-586

Kim JH, Yamaguchi K, Lee SH, Tithof PK, Sayler GS, Yoon JH, Baek SJ (2005) Evaluation of polycyclic aromatic hydrocarbons in the activation of early growth response-1 and peroxisome proliferator activated receptors. Toxicol Sci 85:585-593

Kim SJ, Kweon O, Freeman JP, Jones RC, Adjei MD, Jhoo JW, Edmondson RD, Cerniglia CE (2006) Molecular cloning and expression of genes encoding a novel dioxygenase involved in lowand high-molecular-weight polycyclic aromatic hydrocarbon degradation in Mycobacterium vanbaalenii PYR-1. Appl Environ Microbiol 72:1045-1054

Kim SJ, Kweon O, Jones RC, Freeman JP, Edmondson RD, Cerniglia CE (2007) Complete and integrated pyrene degradation pathway in Mycobacterium vanbaalenii PYR-1 based on systems biology. J Bacteriol 189:464-472

Kim SJ, Song J, Kweon O, Holland RD, Kim DW, Kim J, Yu LR, Cerniglia CE (2012) Functional robustness of a polycyclic aromatic hydrocarbon metabolic network examined in a nidA aromatic ringhydroxylating oxygenase mutant of Mycobacterium vanbaalenii PYR-1. Appl Environ Microbiol 78:3715-3723

Krivobok S, Kuony S, Meyer C, Louwagie M, Willison JC, Jouanneau Y (2003) Identification of pyrene-induced proteins in Mycobacterium sp. strain 6PY1: evidence for two ring-hydroxylating dioxygenases. J Bacteriol 185:3828-3841

Luo L, Lin S, Huang HL, Zhang SZ (2012) Relationships between aging of PAHs and soil properties. Environ Pollut 170:177-182 
Macleod CJA, Semple KT (2000) Influence of contact time on extractability and degradation of pyrene in soils. Environ Sci Technol 34: 4952-4957

Mason JR, Cammack R (1992) The electron-transport proteins of hydroxylating bacterial dioxygenases. Annu Rev Microbiol 46:277-305

Meng LA, Zhu YG (2011) Pyrene biodegradation in an industrial soil exposed to simulated rhizodeposition: how does it affect functional microbial abundance? Environ Sci Technol 45:1579-1585

Mueller KE, Shann JR (2006) PAH dissipation in spiked soil: impacts of bioavailability, microbial activity, and trees. Chemosphere 64:10061014

Niepceron M, Beguet J, Portet-Koltalo F, Martin-Laurent F, Quillet L, Bodilis J (2014) Low impact of phenanthrene dissipation on the bacterial community in grassland soil. Environ Sci Pollut Res 21: 2977-2987

Park JW, Crowley DE (2006) Dynamic changes in nahAc gene copy numbers during degradation of naphthalene in PAH-contaminated soils. Appl Microbiol Biot 72:1322-1329

Peng JJ, Cai C, Qiao M, Li H, Zhu YG (2010) Dynamic changes in functional gene copy numbers and microbial communities during degradation of pyrene in soils. Environ Pollut 158:2872-2879

Peng J, Zhang Y, Su J, Qiu Q, Jia Z, Zhu YG (2013) Bacterial communities predominant in the degradation of ${ }^{13} \mathrm{C}(4)-4,5,9,10$-pyrene during composting. Bioresource Technol 143:608-614

Smalla K, Oros-Sichler M, Milling A, Heuer H, Baumgarte S, Becker R, Neuber G, Kropf S, Ulrich A, Tebbe CC (2007) Bacterial diversity of soils assessed by DGGE, T-RFLP and SSCP fingerprints of PCRamplified 16S rRNA gene fragments: Do the different methods provide similar results? J Microbiol Meth 69:470-479

Suzuki MT, Taylor LT, DeLong EF (2000) Quantitative analysis of smallsubunit rRNA genes in mixed microbial populations via 5'-nuclease assays. Appl Environ Microbiol 66:4605-4614

Tamura K, Peterson D, Peterson N, Stecher G, Nei M, Kumar S (2011) MEGA*5: Molecular evolutionary genetics analysis using maximum likelihood, evolutionary distance, and maximum parsimony methods. Mol Biol Evol 28:2731-2739

Walter U, Beyer M, Klein J, Rehm HJ (1991) Degradation of pyrene by Rhodococcus sp. Uw1. Appl Microbiol Biot 34:671-676

Xu SY, Chen YX, Wu WX, Wang KX, Lin Q, Liang XQ (2006) Enhanced dissipation of phenanthrene and pyrene in spiked soils by combined plants cultivation. Sci Total Environ 363:206-215

Yagi JM, Madsen EL (2009) Diversity, abundance, and consistency of microbial oxygenase expression and biodegradation in a shallow contaminated aquifer. Appl Environ Microbiol 75:6478-6487

Zhang Y, Zhu YG, Houot S, Qiao M, Nunan N, Garnier P (2011) Remediation of polycyclic aromatic hydrocarbon (PAH) contaminated soil through composting with fresh organic wastes. Environ Sci Pollut R 18:1574-1584

Zhong Y, Luan TG, Lin L, Liu H, Tam NFY (2011) Production of metabolites in the biodegradation of phenanthrene, fluoranthene and pyrene by the mixed culture of Mycobacterium sp. and Sphingomonas sp. Bioresource Technol 102:2965-2972 